\title{
Experimentações escolares da política de educação integral e(m) Tempo Integral: uma análise das práticas efetivadas em escolas públicas de Belém - PA
}

\author{
Ney Cristina Monteiro de Oliveira ${ }^{1}$, Orlando Nobre Bezerra de Souza ${ }^{2}$, Izete Magno Correa ${ }^{3}$, Cintia Aurora Quaresma \\ Cardoso ${ }^{4}$ \\ $1,2,3$ Universidade Federal do Pará - UFPA. Núcleo de Estudos Transdisciplinares em Educação Básica (NEB). Rua Augusto \\ Corrêa, 01, Bairro Guamá. Belém - PA. Brasil. ${ }^{4}$ Secretaria de Estado de Educação - SEDUC/PA. \\ Autor para correspondência/Author for correspondence: neycmo@ufpa.br
}

RESUMO. O artigo apresenta a análise feita sobre política de tempo integral implantada na rede estadual de ensino paraense a partir de sua configuração prática na realidade de 02 (duas) escolas de ensino fundamental da cidade de Belém-Pa. Objetivou refletir sobre os princípios da política instituída, a gestão, organização pedagógica e efetivação nas práticas escolares. $\mathrm{O}$ aporte teórico-metodológico deste estudo tem como base a abordagem qualitativa da pesquisa, tendo como procedimentos a análise documental, entrevistas e aplicação de questionários para a compreensão de cada fase da implantação, a percepção dos gestores e docentes, bem como analisar as iniciativas realizadas, os desafios enfrentados, as dificuldades e as possibilidades de inovação pedagógica. Concluiu-se que a política não contou com o apoio oficial devido, ficando a cargo dos educadores a sua efetiva realização. Apesar de pequenos avanços, prevaleceu a inexistência de condições materiais para o desenvolvimento de práticas escolares que qualificassem a oferta do tempo integral para a formação integral dos educandos.

Palavras-chave: Política Educacional, Tempo Integral, Práticas Escolares. 


\title{
School experiments of the integral education policy and Full Time School: an analysis of the practices carried out in public schools of Belém - PA
}

\begin{abstract}
The wording presents the analysis carried out on the full-time policy implemented in the state education network in Pará from its practical configuration in the reality of 02 (two) elementary schools in the city of Belém-Pa. Reflect on the principles of the instituted policy, management, pedagogical organization and effectiveness in school practices. The theoretical-methodological contribution of this study is based on the qualitative approach of the research, having as procedures the documentary analysis, interviews and application of questionnaires to understand each phase of the implantation, the perception of managers and teachers, as well as to analyze the initiatives carried out, the challenges faced, the difficulties and the possibilities of pedagogical innovation. It was concluded that the policy did not have the official support due, leaving the educators in charge of its effective implementation. Despite small advances, the lack of material conditions for the development of school practices that qualified the offer of full time for the integral training of students prevailed.
\end{abstract}

Keywords: Educational Policy, Full Time School, School Practices. 


\section{Experiencias escolares de la política de educación integral y(m) Tiempo Integral: un análisis de las prácticas realizadas en las escuelas públicas de Belém - PA}

RESUMEN. El texto presenta el análisis realizado sobre la política de tiempo integral implementada en la red de educación del estado de Pará desde su configuración práctica en la realidad de 02 (dos) escuelas primarias de la ciudad de Belém-Pa. El objetivo es reflexionar sobre los principios de la política instituida, la gestión, la organización pedagógica y la efectividad en las prácticas escolares. El aporte teórico-metodológico de este estudio se fundamenta en el enfoque cualitativo de la investigación, teniendo los procedimientos el análisis documental, entrevistas y aplicación de cuestionarios para comprender cada fase de la implantación, la percepción de (directores o gerentes) y docentes, así como analizar las iniciativas realizadas, los desafíos enfrentados, las dificultades y las posibilidades de innovación pedagógica. Se concluyó que la política no contó con el respaldo oficial debido, dejando a los educadores a cargo de su efectiva implementación. A pesar de los pequeños avances, prevaleció la falta de condiciones materiales para el desarrollo de prácticas escolares que calificaran la oferta de tiempo integral para la formación integral de los estudiantes.

Palabras clave: Política Educativa, Tiempo Integral, Prácticas Escolares. 


\section{Introdução}

O presente artigo apresenta análises realizadas a partir do Projeto de Pesquisa Experimentações escolares da Política de Educação de Educação Integral e(m) tempo integral: uma análise das práticas efetivadas em escolas públicas de Belém Pará" (2017-2019) desenvolvido no Grupo de Estudos e Pesquisas sobre Estado e Educação na Amazônia GESTAMAZON/ICED/NEB/UFPA, fruto de um trabalho desenvolvido no ensino de Graduação e na Pós-Graduação em Currículo e Gestão da Escola Básica, além do envolvimento dos profissionais das escolas da rede pública de Belém-PA.

Apresentamos inicialmente os objetivos pretendidos, a recuperação conceitual adotada, a organização metodológica do estudo e em seguida as análises realizadas no estudo da caracterização da realidade de 2 (duas) escolas públicas da Rede Estadual de Ensino da cidade de Belém-Pa, buscando refletir sobre a política instituída, a gestão, organização pedagógica e efetivação nas práticas escolares, demarcando a busca da oferta de um ensino inovador, de qualidade, em tempo integral, dando concretude às políticas educacionais a partir das possibilidades concretas de sua estrutura e funcionamento.
O aporte teórico-metodológico deste estudo se inscreve em análises que indicam que as políticas públicas devem ser entendidas como processo e produto que envolvem articulações entre textos e processos, com possíveis realizações negociadas, constituídas de valores, ideologias, poder e contradições. Tem abordagem no ciclo de políticas proposto por Stephen J. Ball e Mainardes (2011), ao considerar o processo de formulação de políticas como um ciclo contínuo, no qual as políticas são formuladas e recriadas.

Para tanto tomamos como pontos a serem destacados na pesquisa a análise da concepção de educação integral contida na política oficial paraense e a compreensão dos sujeitos escolares sobre a política; o mapeamento das ações efetivamente implementadas pelas escolas que se coadunaram aos princípios da política anunciada; e como as práticas de gestão escolar puderam efetivar a política proposta.

Para tanto a pesquisa pautou-se numa abordagem qualitativa de investigação, partindo inicialmente da revisão da bibliografia para aprofundar os estudos sobre o conceito de educação Integral e(m) Tempo, Integral, bem como o estudo e análise das experiências consolidadas na história da educação brasileira e as 

educação integral e $(m)$ Tempo Integral: uma análise das práticas efetivadas em escolas públicas de Belém - PA...

expressões desta política em nosso Estado. Em seguida fizemos acompanhamento da política em duas (02) escolas, aqui denominadas como Escola A e B, para acompanhar as atividades de tempo integral realizadas no cotidiano dessas unidades, bem como a coleta e análise de documentos produzidos nas mesmas, para compreender as ações planejadas e sua efetivação nas escolas. A apreensão do conteúdo manifesto nos documentos primou por uma análise que pudesse desvelar o conteúdo latente contido nos achados empíricos (Triviños, 1987).

A pesquisa também se debruçou sobre os documentos do planejamento das escolas, entre eles: o relatório de gestão, o Projeto Político Pedagógico - PPP e os projetos desenvolvidos na ampliação da jornada escolar. Levantou-se também dados oficiais de matrícula e fluxo escolar, os indicadores de desempenho escolar: aprovação, reprovação e evasão; o número de professores atuantes nas escolas, sua formação, vínculo funcional, lotação e carga horária com a implantação do tempo integral.

Além do estudo dos documentos, pudemos acompanhar algumas atividades nas escolas ao longo de 2018/2019, participamos de diversas reuniões, semanas de planejamento pedagógico, eventos, bem como realizamos 04 (quatro) entrevistas semi-estruturadas com a equipe gestora das duas escolas. Foi necessário ainda aplicar o instrumento de pesquisa questionário com todos os docentes das escolas (15 professores da escola "A" e por 11 professores da Escola “B”). $\mathrm{O}$ instrumento obedeceu ao modelo semi-estruturado, com 18 questões fechadas e 04 em aberto, para a livre expressão dos professores.

A aplicação do questionário fez-se necessária para a coleta junto aos docentes sobre a compreensão de educação integral partilhada, o significado de tempo integral e sua efetivação na escola, as atividades por eles desenvolvidas que caracterizavam a proposta pedagógica do tempo integral, além de inquirir sobre a organização pedagógica das atividades desenvolvidas no tempo integral, a positividade e o enfrentamento das dificuldades na realização da proposta.

As respostas dos depoentes, tanto das entrevistas quanto dos questionários, foram tratadas a partir das categorias analíticas da pesquisa definidas em: Educação Integral e Tempo Integral, a fim de analisar as compreensões referentes à política oficial proposta. Para isso, utilizamos a técnica de Análise de Conteúdo como método de tratamento e análise da informação. Procurou-se destacar de forma sistemática e qualitativa, os conceitos e as práticas revelas pelos sujeitos que deram a materialidade à política. Explorou-se 
também as interpretações inferenciais, a análise reflexiva e crítica revelada pelos participes (Bardin, 2011).

\section{Educação Integral e Escola de Tempo Integral: concepções e práticas efetivadas na escola pública paraense}

O estudo sobre o conceito de Educação Integral e das políticas de escolarização em tempo integral desenvolvidos no Brasil a partir dos anos 1940 revelaram que acumulamos diferentes perspectivas teóricometodológicas para determinar a efetivação de uma educação integral ou em tempo integral. Para Cardoso (2018) o conceito de educação integral e/ou de tempo integral é uma reflexão complexa, podendo ser entendido por diferentes perspectivas, intenções e concepções, como afirma Ribeiro (2017):

No âmbito societário mais geral, a ideia de educação integral remonta à antiguidade clássica. $\mathrm{Na}$ educação grega, objetivada por meio da Paideia, já se pensava em uma formação humana integral como ideal pedagógico a ser desenvolvido na formação dos seres sociais daquele país. Nesse contexto, a educação integral consistia na valorização dos vários aspectos da vida humana durante o processo educativo (p. 36).

Ligada a esta mesma concepção, Ferreira (2016) explica que tomando por base o ideal de homem forjado pelos gregos é possível compreender a Paidéia como processo formativo, no sentido de dar forma e modelar física e espiritualmente homens virtuosos e heroicos. Esse ideal educativo grego estava pautado na concepção de ética e de política, derivadas de uma vida coletiva, logo, o homem como cidadão precisava ser formado para conviver em sociedade.

Sousa (2016) complementa ainda que o conceito mais tradicional encontrado para a definição de educação integral é aquele que considera o sujeito em sua condição multidimensional, não apenas na sua dimensão cognitiva, como também na compreensão de um sujeito que é sujeito corpóreo, tem afetos e está inserido num contexto de relações socioculturais. Entendemos, portanto, que a Educação Integral deve compreender um sujeito que precisa ser percebido em suas múltiplas dimensões, um sujeito histórico, sujeito de seu tempo, sujeito de cultura e um ser biopsicossocial.

No que tange o processo de efetivação das práticas pedagógicas do tempo integral, Cavaliere (2002, p. 249) propõe uma nova identidade à escola, para que a mesma não consista apenas em aprimorar o processo cognitivo da criança, mas também promover a construção de um indivíduo em plenitude, levando em conta os aspectos sociais, afetivos, culturais. Por 

educação integral e $(m)$ Tempo Integral: uma análise das práticas efetivadas em escolas públicas de Belém - PA...

este motivo, Maurício (2009, p. 27) diz que "a escola precisa ser convidativa", ou seja, precisa ser um ambiente prazeroso ao aluno, principalmente àquele onde 0 espaço de lazer e convivência é restrito. A autora ainda afirma que "tirar a criança da rua pode ser uma consequência deste fato, mas não um objetivo, que poderia redundar numa proposta de enclausuramento assistencial".

Os estudos feitos destacam ainda que a oferta da Educação Integral ou da escola em Tempo Integral embora seja um assunto muito discutido atualmente, enquanto política pública ainda é recente na história da educação brasileira, uma vez que reflexões sobre uma formação mais completa do ser remonta ao início da civilização humana, pois ao estudarmos a Paidéia grega perceberemos "a formação humana mais completa" já continha o germe que mais tarde denominou educação integral (Coelho, 2009, p. 85).

De acordo com Sousa (2015), a proposta de educação integral/em tempo integral numa perspectiva de transformação social é resgatada no final do século XX, nos pensamentos de intelectuais marxistas. Nesta defesa, encontramos Paolo Nosella e Gaudêncio Frigotto que dão suas contribuições à análise da politécnica e escola do trabalho.
Para Frigotto (2009), a educação politécnica ou tecnológica deveria desenvolver uma formação científica, técnica e política cujo conteúdo, método e forma manifestem-se na direção contrária à perspectiva de subordinação das relações sociais e educativas ao capitalismo.

Deste modo, entendemos que Frigotto defende uma escola para todos, que articule ciência, trabalho e cultura, não numa perspectiva pragmática, mas que "permitam analisar, compreender o mundo da natureza, das coisas, e o mundo humano/social, político, cultural estético e artístico" (Frigotto, 2012, p. 249), o que permitiria superar o viés economicista e mecanicista.

A partir do século XXI surgiram outras experiências de educação integral/em tempo integral, em alguns estados e municípios. Entres as iniciativas temos: o Programa de Educação Integral em Apucarana/Paraná, os Centros Educacionais Unificados (CEUs) em São Paulo, o Programa Escola Integrada (PEI) em Belo Horizonte e o Bairro-escola em Nova Iguaçu.

Essa percepção de Educação Integral, mesmo que de forma indireta, aparece nos estudos com frequência, visto que mesmo tendo fundamentações teóricas e concepções diferentes, os autores acabam por enfatizar que a Educação Integral visa 
à formação de um "sujeito completo", como disposto na LDBN 9394/96:

Art. $1^{\circ}$. A educação abrange os processos formativos que se desenvolvem na vida familiar, na convivência humana, no trabalho, nas instituições de ensino e pesquisa, nos movimentos sociais e organizações da sociedade civil e nas manifestações culturais.

Art. $2^{\circ}$. A educação, dever da família e do Estado, inspirada nos princípios de liberdade e nos ideais de solidariedade humana, tem por finalidade o pleno desenvolvimento do educando, seu preparo para o exercício da cidadania e sua qualificação para o trabalho. (Lei 9.394, 1996, p. 1).

Desse modo, Vasconcelos (2016) afirma que política de Educação Integral no Brasil se consolidou, na maioria das experiências, na ampliação de tempo para oportunizar novas e significativas aprendizagens. Um marco inicial da educação escolar de tempo integral está na obra de Anísio Teixeira e se fez presente desde o Manifesto dos Pioneiros da educação Nova em 1932. A experiência realizada em Salvador nos anos 1940 no Centro Educacional Carneiro Ribeiro, marcou o início de um projeto de escola em tempo integral que influenciou outras iniciativas realizadas no país desde então.

Vale ressaltar que as iniciativas governamentais em adotar medidas de ampliação do tempo escolar se devem à preocupação com a qualidade do ensino oferecido, devido aos baixos índices educativos, e também pelo fato de a escola pública brasileira estar distante da realidade dos alunos, especialmente das classes populares, o que demanda novos desafios para os espaços educativos (Cavaliere, 2009).

Os estudos também atestam que a maioria das experiências implementadas no país não tiveram fôlego para dar continuidade aos seus programas, diante de situações que abalaram frontalmente as propostas como, por exemplo: as mudanças de gestão, insuficiência e precariedade de verbas direcionada para escolas de tempo integral, dificuldades de ordem administrativo, pedagógico e financeiro dos programas, às descontinuidades das políticas públicas, entre outras, contribuindo de maneira decisiva para descontinuidade das experiências.

Em verdade, trata-se de uma base nova de fundamentação e prática educacional, um desafio a ser enfrentado no "chão da escola" pública, o que requer estudos que possam revelar as formas como as quais as escolas tem enfrentado esses processos e as dinâmicas organizacionais instituídas para a realização do seu projeto educativo.

É a partir das experiências históricas e dos marcos normativos educacionais pós 
Constituição de 1988 e da LDB 9.394/1996, que localizamos a recente política de implantação da escola em tempo integral no Pará quando a Secretaria de Estado de Educação - SEDUC - PA aderiu a dois programas federais, o Programa Mais Educação - PME em 2008, voltado para o atendimento das matrículas no Ensino Fundamental e o Programa Ensino Médio Inovador - ProEMI em 2010, que eram voltados tanto para a ampliação da jornada escolar quanto para a reestruturação curricular das escolas.

Por meio deles, as escolas adequaram os projetos pedagógicos às possibilidades de oferta de atividades complementares pelos programas, buscando articular novas propostas pedagógicas que viessem contribuir para um redesenho da escola, pautado na construção coletiva de conhecimento a partir da participação social.

Esse movimento de educação integral trouxe a necessidade de uma nova configuração de currículo, bem como ampliação de funções e tempos escolares moldando involuntariamente uma nova identidade para as escolas, haja vista, que este processo envolveu diversos atores e fatores que reconstruíram o ritmo das escolas, antes da implementação dos Programas.
No caso do Estado do Pará, o debate da oferta de educação em tempo integral foi referendado no processo de constituição de seus dois Planos Estaduais de Educação - PPE. Um primeiro, aprovado em 2010, Lei $n^{\circ} 7.441$, de 2 de julho de 2010, fruto de intensa participação social ocorrida por força da realização de conferências municipais em 2007, e da Conferência Estadual de 2008, sendo que naquele momento, os órgãos do sistema de educação paraense procuravam sanar uma lacuna, visto que o PNE já estava em vigor desde 2001 e o Pará ainda não tinha o seu Plano Estadual.

Importa destacar ainda, que antes da aprovação da Lei 7.441/2010 (PEE-PA), já havia no Pará experiências de escolas que ofertavam a educação em tempo integral, por meio PME do Governo Federal, implantado em 2009 em vários municípios. Essas experiências ocorreram tanto na capital (Belém), quanto nos municípios como Abaetetuba, Santarém, Igarapé-Miri, Oriximiná e outros.

A oferta da educação escolar em tempo integral, apesar de contemplada de maneira tímida no Plano Estadual de 2010, fez com que a SEDUC aprovasse, em 2012, duas resoluções que passaram a nortear a política de oferta da escola em tempo integral, documentos que orientaram 
as ações nas escolas para a implantação do tempo integral.

Assim, para o cumprimento das determinações normativas do PEE/2010, a SEDUC, em 2012, se utilizou das Resoluções $n^{\circ} \quad 002 / 2012^{i} \quad(2012 a) \quad$ e $003 / 2012^{\text {ii }}$ (2012) e implantou o piloto do "Projeto Escola de Tempo Integral" em 14 (quatorze) escolas da rede estadual, 9 (nove) delas de Ensino Fundamental, 4 (quatro) de Ensino Médio regular e 1 (uma) de Educação Profissional, todas situadas na região metropolitana de Belém. Dessas, destacaremos nos itens a seguir, 02 (duas) que se tornaram o centro de nosso debate, para discutir os movimentos gerados por esta política na gestão das escolas.

Desse modo, o Governo do Estado do Pará aprovou em 2012, a Resolução Estadual $n^{\circ}$ 002/2012-GS/SEDUC, que dispunha sobre o Projeto de Escola de Tempo Integral, em cumprimento à política nacional de ampliação da jornada escolar, prevista nos dispositivos legais como a LDB 9.394/96 e o Plano Nacional de Educação:

I - Promover a permanência do educando na escola, assistindo-o integralmente em suas necessidades básicas e educacionais, reforçando o aproveitamento escolar, a autoestima e o sentimento de pertencimento;

II - Intensificar as oportunidades de socialização na escola;
III - Proporcionar aos alunos alternativas de ação no campo social, cultural, esportivo e tecnológico;

IV - Incentivar a participação da comunidade por meio do engajamento no processo educacional implementando a construção da cidadania;

$\mathrm{V}$ - Adequar as atividades educacionais à realidade de cada município, desenvolvendo o espírito inovador, criativo e crítico aos educandos (Resolução 02/2012, Art. $\left.2^{\circ}\right)$.

Percebemos que a resolução buscava prolongar a permanência dos alunos da Educação Básica, oportunizando o desenvolvimento de atividades no campo social, cultural, esportivo e tecnológico na perspectiva de promover e ampliar as possibilidades de aprendizagem.

Assim, ao iniciarmos a pesquisa nas escolas entendemos que tal documento se limitou a estender o tempo de permanência dos alunos na escola, como a possibilidade de melhoria no desempenho no processo de aprendizagem; no entanto, não levou em consideração a precarização das condições de trabalho enfrentadas pela maioria dos docentes, além do sucateamento e a falta de investimentos nas escolas incluídas no Projeto de Educação em Tempo Integral do Estado.

Importa destacar que a referida Resolução apresentava alguns princípios norteadores para a elaboração de PPPs, dentre os quais se destacou os objetivos do Projeto Escola de Tempo Integral, 
prescritos no artigo $2^{\circ}$ da Resolução 002/2012:

I - promover a permanência do educando na escola, assistindo-o integralmente em suas necessidades básicas e educacionais, reforçando o aproveitamento escolar, a autoestima e o sentimento de pertencimento; II intensificar as oportunidades de socialização na escola; III proporcionar aos alunos alternativas de ação no campo social, cultural, esportivo e tecnológico; IV incentivar a participação da comunidade por meio do engajamento no processo educacional implementando a construção da cidadania; V - adequar as atividades educacionais à realidade de cada município, desenvolvendo o espírito inovador, criativo e crítico aos educandos (Resolução 02/2012, p. 2).

Outro aporte legal do processo de implantação da política de ampliação do tempo escolar na Rede Estadual de Educação do Pará foi a Resolução 003/2012, que tratou da organização e do funcionamento da Escola de Tempo Integral, cabendo salientar que o documento apresentou maior precisão no que dizia respeito à estrutura curricular da referida proposta.

É importante salientar ainda, que a Resolução 003/2012 foi um documento de grande importância para que as escolas passagem a fazer parte do Projeto Piloto Escola de Tempo Integral. Entretanto, ressaltamos que nem na Resolução 002/2012, nem na Resolução 003/2012, encontramos a presença de um referencial teórico consistente sobre educação em tempo integral, o que comprometeu seu embasamento, além de ocasionar um empobrecimento dos referidos documentos.

Assim, diante desse desafio, percebemos que na história recente da escola brasileira à oferta do tempo integral, as unidades educativas foram levadas a criar novos caminhos, engendrar novas práticas, subverter a ordem dos acordos firmados, ou, muitas das vezes, adequar-se, e procurar nas "brechas" do sistema, maneiras para desenvolver suas ações, como é o caso das Escolas pesquisadas, que aqui denominaremos como Escola " $A$ " e Escola "B".

A viabilidade dessa política nas escolas que participaram da proposta piloto e as ações da gestão engendradas nas práticas escolares é o que traremos em análise a seguir.

\section{Caracterização da Escola "A" e a precariedade experimentada no Tempo Integral:}

Nesta subseção daremos destaque à Escola "A", primeira a ser pesquisada, fundada em 1993 a partir do modelo de escola de tempo integral inspirado nas experiências dos CIEPs-Centros Integrados de Educação Públicas, de autoria do Antropólogo Darcy Ribeiro, implantados inicialmente no Rio de Janeiro, cujo 
modelo foi herdado dos CIACs/CAICs Centro de Atenção Integral à Criança e ao Adolescente dos anos do Governo Collor (1990-1992), que tanto em sua arquitetura, quanto no formato pedagógico, foi projetada para funcionar em tempo integral embora funcionasse em tempo parcial.

Somente em 2012 o tempo integral foi implantado pela Secretaria de Educação do Pará e a partir da Resolução número 002/2012-GS/SEDUC a escola teve sua jornada estendida.

No PPP (2015, p. 09) da Escola, percebe-se que em relação à estrutura curricular tanto a equipe gestora quanto os docentes, buscavam uma proposta que pudesse favorecer o desenvolvimento dos educandos em todas as dimensões, por meio das "capacidades afetiva, física, cognitiva, ética, estética, espiritual, de inter-relação pessoal e de inserção social, para agir com perseverança na busca do conhecimento e no exercício da cidadania".

A perspectiva de um trabalho minimamente integrado foi referenciada em Relatório anual (2015) no qual a equipe registrou que o Programa Mais Educação oportunizou a articulação das atividades curriculares. Contudo, com a interrupção das ações do Programa em 2015 a Escola buscou outros caminhos para que o currículo continuasse sendo efetivado sob a mesma orientação. Porém, apesar do Relatório não apresentar vinculações com o PPP da escola, ficou perceptível que após a interrupção do Programa PME os projetos seguiram o mesmo modelo experimentado, mas sem o aporte financeiro, o que lhes trouxe maiores dificuldades na execução.

\section{A compreensão de Tempo Integral captada dos gestores e docentes da Escola "A":}

Nesta subseção trataremos dos conceitos sobre Tempo integral compreendido pelos profissionais da Escola "A", os processos vividos no período de implantação e as dinâmicas empreendidas pela equipe gestora e docentes, da Escola em análise, para a efetivação da política. Para essa análise trouxemos as compreensões reveladas em questionário aplicado ao corpo docente e as entrevistas realizadas com a equipe gestora.

Ao analisar os questionários com as respostas dos professores percebemos que em relação aos documentos que regiam a Escola 53,3\% dos professores afirmaram desconhecer o regimento escolar, considere-se ainda que $40 \%$ dos docentes afirmaram ter pouco conhecimento sobre o PPP da Escola, tão pouco sobre a proposta curricular e a proposta de tempo integral da SEDUC. 

educação integral e(m) Tempo Integral: uma análise das práticas efetivadas em escolas públicas de Belém - PA...

Ao serem indagados sobre o conceito de Educação Integral, 50\% entendem que é o mesmo que ampliação da jornada escolar de seus estudantes, visando formação diferenciada do indivíduo ao oportunizar mais tempo e outros espaços multidisciplinares para uma formação mais dinâmica e criativa. Outros $28 \%$ destacaram que é uma escola que oferece um tempo maior para melhor aprendizagem dos alunos através de atividades diferenciadas, $13 \%$ afirmaram que é a ampliação do tempo aliado a ações educacionais que atendam aos anseios da comunidade, promovendo a interação dos alunos, com múltiplas oportunidades de aprendizagem.

Em relação às atividades realizadas na escola, $67 \%$ dos docentes afirmaram que promoviam projetos e atividades de cunho cultural, esportivo ou artístico com seus alunos no tempo integral, mas $80 \%$ destes afirmaram que não desenvolviam mais atividades devido a carência de infraestrutura adequada, afirmaram que a precariedade dos espaços e o sucateamento das salas ambiente impediam sua realização. Perguntados sobre a proposta pedagógica da escola, e sobre qual projeto ou atividade foram executadas nos últimos 2 anos, $40 \%$ responderam que as atividades estavam voltadas para os projetos internos e externos (sugeridos pela Secretaria), atendendo as necessidades educacionais dos alunos, mas não detalharam que necessidades eram estas tão pouco expressaram a compreensão sobre a pertinência destas ao projeto da escola de tempo integral.

Das entrevistas realizadas com a 02 (duas) gestoras da escola percebeu-se que elas tinham enorme dedicação ao trabalho e procuraram dar todo apoio aos docentes, mas percebiam seus limites pois a escola tinha grandes problemas de espaço-físico, que impedia a realização de atividades, além de não oportunizar um ambiente agradável para uma permanência de mais de 07 (sete) horas para as crianças. Enfatizaram a qualidade dos docentes, mas ressentiam-se de não terem recebido maior apoio para a realização da proposta. As gestoras compreendiam que o tempo integral poderia significar a oferta de uma educação mais ampliada, mas sem o aporte financeiro e pedagógico a tarefa tornava-se "quase impossível".

Em resumo, a análise dos dados revelou certo desconhecimento geral dos fundamentos pedagógicos da educação integral e da oferta em tempo integral por parte dos professores, percebeu-se que a implantação da política não foi objeto de um tratamento no interior do projeto pedagógico, foi revelado ainda que os docentes não se sentiam preparados e nem 

educação integral e $(m)$ Tempo Integral: uma análise das práticas efetivadas em escolas públicas de Belém - PA...

receberam capacitação para desenvolver as atividades desejadas. Os dados revelaram a precariedade na infraestrutura como um obstáculo às atividades, pois não houve investimento do Estado na implantação das condições adequadas ao projeto de tempo integral, o que indicou que uma política desta natureza não poderia ser implantada sem um padrão mínimo de qualidade para que fosse levada a efeito.

\section{Caracterização da Escola "B" e as limitações estruturais para a implantação do Tempo Integral}

Nesta subseção daremos destaque à segunda Escola pesquisada, a Escola, "B", que foi fundada em 11 de março de 1971, sob a Resolução no 32/37 do Conselho Estadual de Educação, situada em bairro periférico da cidade de Belém - PA. Desde sua fundação a escola funcionava com 3 turnos de $1^{\mathrm{a}}$ e $4^{\mathrm{a}}$ séries $\left(1^{\mathrm{o}}\right.$ ao $5^{\mathrm{o}}$ ano $)$ do Ensino Fundamental e EJA (Educação de Jovens e Adultos).

Em 2013, foi mais uma das escolas selecionadas para realizar o projeto piloto da SEDUC, começando suas primeiras experiências no projeto de tempo integral, com os subsídios financeiros e técnicos do Programa Mais Educação, passando a atender 7 turmas no tempo integral, cumprindo uma jornada de 9h30min, tempo superior ao recomendado pelo Decreto de no. 6.253/2007 do Fundo de
Manutenção e Desenvolvimento da Educação Básica e de Valorização dos Profissionais da Educação (FUNDEB), o qual considerava “educação básica em tempo integral a jornada escolar com duração igual ou superior a 7 (sete) horas diárias, durante todo o período letivo, compreendido o tempo total que um mesmo aluno permanece na escola ou em atividades escolares".

Igualmente à experiência da Escola "A", os projetos desenvolvidos pela Escola " $B$ " foram originários do período em que recebiam recursos do PME (Programa Mais Educação), que deixou um "certo" modelo de atuação na execução do tempo integral, visto que não havia outro modelo orientado para que a escola repensasse sua proposta pedagógica com a implantação do tempo integral.

Nesta Escola tivemos acesso às Atas das reuniões com o Conselho Escolar, foram 12 (doze) atas estudadas e 03 (três) reuniões da equipe pedagógica com os professores, e delas pudemos perceber o desenvolvimento da política no interior da escola, as dificuldades, limites e possibilidades para implantação do projeto de escola integral e(m) tempo integral, percebendo também as possibilidades exitosas desta política no Estado do Pará, se tivesse contado com o apoio institucional devido. 
As Atas revelaram a Secretaria Estadual esteve na escola para atribuir as providências que deveriam ser tomadas para a organização temporal e espacial para a oferta do tempo integral, a reorganização das turmas. Após 04 (quatro) meses de início das atividades, em uma das reuniões registradas, foram destacados os pontos positivos do projeto tais como a permanência e integração entre os alunos e como negativos como o cansaço das crianças, a oferta precária da alimentação escolar, o desconforto nas instalações físicas da escola (salas de aula quentes), a insuficiência de funcionários (cuidadores, cozinheiras) para o trabalho na escola.

As Atas registraram ainda que para o atendimento às necessidades mínimas dos alunos foi solicitado aos pais e responsáveis a ajuda dos familiares para trabalharem voluntariamente no apoio ao cuidado das crianças, na orientação e inclusão de hábitos cotidianos dos filhos, na doação de colchonetes para o descanso das crianças, dentre outros.

$\mathrm{Na}$ continuidade das atividades em tempo integral as atas revelaram que incluiu-se na pauta da gestão escolar o controle da aprendizagem dos alunos e seus reflexos nas avaliações externas, uma preocupação que levou a equipe pedagógica a propor como atividades no tempo integral tão somente o reforço de tarefas escolares, priorizando os conteúdos disciplinares, visando a melhoria da proficiência em Língua Portuguesa e Matemática, vinculando assim as atividades didáticas às motivações da melhoria de desempenho nos exames nacionais externos.

Percebe-se que esta medida acabou transformando as atividades complementares e formativas do tempo integral em componentes curriculares para atendimento aos padrões gerenciais da avaliação de resultados, da competitividade e ranking como novo modelo de gestão para a qualidade do ensino. Esta prática de gestão afastou totalmente a escola dos princípios da educação integral em tempo integral, que objetiva a formação plena dos sujeitos e não apenas o alcance de índices de mercado.

Outro ponto que mereceu destaque em reunião do Conselho Escolar foi quando se estabeleceu a necessidade de agregar parcerias da escola com a comunidade e instituições, para suprir as necessidades da escola, isentando-se do debate a responsabilização do Estado para com a política educacional implantada. Vêse aqui a lógica do Estado mínimo, da qualidade atestada no ranking dos resultados nos exames nacionais e de qualidade de ensino vinculada a uma visão 
instrumental de oferta de serviços tomando a cena e exigindo que a escola procure encaminhar suas ações a partir da arrecadação de recursos privados.

A proposta de tempo integral vinculada à melhoria da qualidade nos resultados dos exames nacionais também está no Plano de Ação da Gestão de 2018, ao enfatizar que os projetos de melhoria no ensino-aprendizagem devem ter como propósito "a melhoria do Ideb da escola". O Plano citado não trata da proposta de tempo integral na integração de saberes ou na criação de oportunidades educativas amplas às crianças em formação, o que já revela uma débil articulação entre a política pretendida e a ação planejada pela escola.

As atas de 2018 também retratam o abandono da política por parte da Secretaria estadual ao não manter a contratação dos profissionais de apoio, além da ausência do fornecimento regular da alimentação escolar. O Estado não conseguiu prestar as mínimas garantias para o bom funcionamento da escola em tempo integral e esses fatos revelam os problemas existentes anteriormente tais como, a infraestrutura, a alimentação, carência de funcionários, dentre outros. Assim, podemos inferir que em anos de existência do projeto ETI na instituição quase nada foi feito no sentido de resolver, ou no mínimo melhorar as condições materiais, pedagógicas e físicas da instituição para permanência com sucesso dos alunos.

Essa realidade apresentada nas atas revela ainda que a SEDUC - PA implementou o Projeto Escola de Tempo Integral na instituição, com grande descaso e irresponsabilidade com a qualidade da educação pública. Costa (2015) em análise do Projeto de Educação em Tempo Integral da SEDUC do Pará, concluiu que houve descaso e inabilidade técnica e pedagógica da Secretaria Estadual de Educação em conduzir e executar o projeto ETI, abandonando as escolas à própria sorte.

$\mathrm{Na}$ realidade da Escola B percebeuse os desafios enfrentados pelas escolas públicas paraenses na implantação da política de tempo integral, com especial destaque: a falta de infraestrutura das escolas e de financiamento para o pleno atendimento das demandas da política, a falta de formação e a valorização da ação docente, a frágil articulação entre o Programa e PPP da escola, entre outros.

\section{O tempo integral revelado pela direção $e$ pelos docentes da Escola "B":}

A Escola "B" começou suas primeiras experiências de tempo integral com a implantação do Programa Mais Educação - PME em 2013, quando passou a atender uma parcela de alunos no tempo 
integral e outra em período regular. Vale registrar que o PME só funcionou com o apoio técnico e financeiro até 2016. Depois desse ano a escola continuou a oferta do tempo integral sem os aportes recebidos pelo Programa, enfrentando uma série de dificuldades, mas ainda assim manteve as atividades como estratégias próprias para permanecer com o tempo integral.

Essa organização do tempo nos chamou atenção e passamos a tentar compreender o processo pelo qual a Escola passou desde o início do PME e como se configurou o tempo integral no local. Para tanto, algumas questões foram esclarecidas a partir de entrevista realizada com a Diretora sobre como se deu a organização do trabalho da gestão nos espaços da escola. Com a entrevista foi possível analisar como a gestão assumiu a organização desse processo, mostrando seus limites e possibilidades para lidar com o tempo integral implantado na instituição de ensino.

Quando perguntada sobre o processo de planejamento e organização da gestão para essa nova dimensão do tempo na escola, a Diretora nos afirmou que a comunidade escolar ainda estava vivendo esse processo e que ao longo dos anos ela vinha tentando organizar um planejamento global no início de cada ano letivo, na Jornada Pedagógica, quando eram debatidos os projetos e os meios para sua execução no tempo integral. Logo que perguntada sobre o apoio financeiro para fazer as adaptações necessárias ao tempo integral, a ela respondeu que não houve qualquer apoio financeiro por parte da SEDUC e que contaram com a ajuda da comunidade para realizar atividades que pudessem custear os gastos que as atividades em tempo integral demandavam para serem efetivadas. É perceptível então que a direção enfrentava grandes desafios diante da inexistência de recursos financeiros e da falta de manutenção da infraestrutura para ofertar a educação integral e(m) tempo integral.

Quando questionada sobre se os professores receberam alguma formação por parte da SEDUC-PA, para trabalhar com essa política de tempo integral, a Diretora foi categórica em dizer que os docentes não receberam qualquer formação por parte dos órgãos responsáveis e que apenas participaram de formações de outros programas governamentais, o que ajudou em parte nas práticas pedagógicas desses docentes. Tal relato nos leva a perceber que o projeto de escola $\mathrm{e}(\mathrm{m})$ tempo integral foi deixado à responsabilidade da própria escola, tanto para sua implantação, organização, estrutura material e capacitação dos 
professores, sem receber o devido suporte necessário do Estado.

Um dos desafios enfatizados pela Gestora referiu-se à execução do tempo integral, relacionado à organização do período de aula e ao currículo estabelecido na resolução proposta para o tempo integral. O documento citado pela Diretora dispõe sobre o Projeto, organização e funcionamento da escola de tempo integral, bem como as atividades desenvolvidas atentando para a nova demanda para a escola:

Na organização da Escola de Tempo Integral, observar-se-á:

I- Regime de estudos em período integral: manhã e tarde;

II- Carga horária semanal de 45 aulas;

III- total de aulas diárias: 09 aulas IV- Jornada diária discente: 09 horas, com intervalos de uma hora para almoço e vinte minutos, em cada turno, para recreio. (Resolução 003/2012).

Para a Direção, a dificuldade sempre esteve em não possuir espaços adequados para os intervalos, pessoal para dar assistência às crianças, orientação aos professores para que pudessem propor atividades adequadas que pudessem configurar novas dinâmicas de aprendizagem para contribuir com a formação integral dos sujeitos.

A esse respeito aderimos às orientações de que a escola deve apresentar infraestrutura e espaços adequados à permanência de estudantes e profissionais em tempo integral, além desta questão é indispensável formação continuada e tempo regular de planejamento coletivo para todos os profissionais que atuam na escola de tempo integral.

Acreditamos, portanto, que a escola de tempo integral, ainda que passível de aprimoramentos, satisfações e insatisfações para os sujeitos que a compõem, precisa ser planejada, organizada e preparada para assumir tal proposta. $O$ que vimos acontecer na Escola " $A$ " se repete na Escola "B", quando um dos maiores entraves para a realização plena da proposta foi o pouco apoio institucional, bem como a falta de orientação pedagógica, um plano de ação para o processo de implantação da proposta e um processo de formação dos docentes diante de uma nova dimensão didáticopedagógica.

$\mathrm{Na}$ análise do depoimento dos docentes, percebemos que eles apontam algumas reflexões sobre a falta de apoio estrutural necessário para o Projeto de Escola em Tempo Integral, pois os educadores compreendiam que para a efetivação da proposta na Escola, seria necessário atender as demandas de infraestrutura física, financeira, de alimentação escolar e de pessoal para o desenvolvimento das atividades, além do 
comprometimento da gestão e seu envolvimento com a proposta e as práticas pedagógicas na condução desse processo.

No caso da Escola B, foi a comunidade quem reuniu e fez atividades para arrecadar recursos para adequação das salas de aula, aquisição dos colchonetes, para complementação da alimentação diária e compra de material didático para os jogos e outras atividades.

Em nossa análise constatamos que desde a sua implantação até seu planejamento e organização, a escola de tempo integral foi e ainda é um grande desafio para as unidades que estão executando a política. Sem o suporte estatal e os princípios norteadores que a política requeria, sem as formações continuadas para pôr em prática todo o trabalho proposto e principalmente sem os recursos financeiros necessários para o projeto, a equipe escolar enfrentava todos os desafios e tentava realizar a 'próprio punho' a proposta, tomando como norte as resoluções pouco claras desse projeto, contando com a disposição e força de vontade da sua comunidade escolar no provimento de algumas condições mínimas.

Aproximações sobre as relações entre o discurso oficial, a compreensão dos profissionais das escolas e a realização da política de tempo integral na escola pública paraense
Para fins conclusivos vale ressaltar que o estudo feito procurou analisar os caminhos efetivados pela política pública no interior das unidades escolares e a identificação das possibilidades da Política de Educação Integral e (em) Tempo Integral experimentadas nas duas escolas da Rede Estadual de Ensino de Belém-Pa, nesse processo importou a escuta dos educadores de 2 (duas) escolas estaduais selecionadas para a implantação da referida política.

As Escolas “A" e "B" aqui retratadas, apesar de escolhidas pela Secretaria de Estado de Educação em 2012 para desenvolver a política, não receberam as bases materiais, humanas e pedagógicas para tal, o que nos levou a compreender que nestas escolas o esforço dos profissionais, a dedicação e o empenho pessoal foram os fatores que ajudaram a materializar esta política.

Segundo os sujeitos entrevistados, a proposta não foi priorizada pela Secretaria de Estado de Educação ao não prover as escolas com os aportes técnicos, humanos e financeiros para a grandiosidade da proposta, tal como previsto. Ao não ser devidamente planejada, não supriu as escolas das bases estruturais para sua implantação e implementação, acabando por deixar a cargo dos educadores e 
gestores a responsabilidade pela sua realização.

Tanto a Escola "A", quanto a "B", assumiram a política educacional com sua capacidade instalada, com seu corpo de profissionais, com uma nova possibilidade de formação dos sujeitos, revisitando o seu projeto pedagógico, incorporando em suas lutas, o direito por uma educação que desenvolvesse o sujeito em sua totalidade, com as condições possíveis.

Se por um lado foi louvável o empenho dos educadores, por outro revelou que não houve comprometimento da gestão pública com a efetivação dos princípios da Política de Educação Integral em Tempo Integral nas escolas selecionadas. $\mathrm{O}$ que possivelmente comprometeu o alcance dos objetivos pretendidos e o cumprimento da garantia da escola pública de qualidade.

Dentre as questões levantadas os depoimentos revelaram que o tempo integral foi redimensionado, principalmente, para atividades de "reforço escolar", sem que os educadores recebessem qualquer orientação ou formação para ter no tempo integral um aliado na efetivação de objetivos de renovação das práticas escolares, ou seja, acabou por reproduzir "mais do mesmo" (Paro, 1988, p. 38).
As percepções compreendidas mostram a busca por uma "ação humanizadora das relações" sem, no entanto, se conseguir projetar ações concretas para a efetividade desse objetivo declarado nas atividades realizadas. Identificam-se diferentes barreiras para o desenvolvimento de práticas escolares de qualidade, tais como a precariedade da infraestrutura disponível, destacando-se o fato de a maioria do corpo docente ser de professores temporários, sem formação adequada e sem preparo para atuar no projeto em tela. Destaca-se na fala dos sujeitos entrevistados a inexistência de um projeto coletivo de ação, capaz de articular e comprometer os diferentes profissionais da escola, motivando docentes e discentes para as atividades de ensino e aprendizagem.

Ainda que num cenário de abandono da escola, importa fazer o registro da total receptividade das escolas para com os objetivos da pesquisa disponibilizando os documentos, prestando todos os esclarecimentos necessários, chamando a equipe para acompanhar suas atividades. As escolas assumiram conosco a pesquisa, disponibilizando tudo o foi solicitado e participando de todas as fases da mesma, das reflexões coletivas partilhadas nas seções de estudo, abrindo-se às visitas e entrevistas, o que culminou na maturidade 
das reflexões conclusivas da pesquisa e, inclusive na produção deste artigo.

Assim, o estudo empreendido procura contribuir para a análise das políticas educacionais que intencionam a implantação do tempo integral como parte integrante da jornada escolar, uma proposta que exige investimentos financeiros para sua efetivação com qualidade, tendo em vista a necessária infraestrutura adequada para acolher os estudantes em uma jornada de 07 (sete) horas diárias, política de alimentação escolar, reorientação curricular, redimensionamento das atividades didático-pedagógicas e para tanto um processo de formação continuada de professores para as inovações pretendidas. Estas são as dimensões elementares para o sucesso de uma política educacional que não foram vivenciadas nas escolas pesquisadas.

\section{Referências}

Alves, A. C. S. (2017). Gastos e Custos do processo de implementação do Ensino Médio em Tempo Integral no Pará (20122015) (Dissertação de Mestrado). Universidade Federal do Pará, Pará.

Bardin, L. (2011). Análise de conteúdo. São Paulo, SP: Edições 70.

Cardoso, C. A. Q. (2018). Programa Novo Mais Educação (2016) e sua concepção de educação em tempo integral (Dissertação de Mestrado). Universidade Federal do Pará, Pará.

Cavaliere, A. M. V. (2002). Educação integral: uma nova identidade para a escola brasileira? Educação \& Sociedade, 23(81), 247-270.

Cavaliere, A. M. (2007) Tempo de escola e qualidade na educação pública. Educação \& Sociedade, 28(100), 1015-1035.

Cavaliere, A. M. V. (2009). Escola de tempo integral versus alunos em tempo integral: educação integral e tempo integral. Em Aberto, 22(80), 51-63.

Coelho, L. M. C. C. (2009). Educação Integral em tempo integral: estudos e experiências em processo. Rio de Janeiro, RJ: FAPERJ, 89-103.

Costa, C. N. (2015). O Projeto Escola de Tempo Integral no Pará: caso da Escola Miriti (Dissertação de Mestrado). Universidade Federal do Pará, Pará.

Decreto $\mathrm{n}^{\mathrm{o}} 7.083$, de 27 de janeiro de 2010, Dispõe sobre o Programa Mais Educação, 2010. Recuperado de: http://www.planalto.gov.br/ccivil_03/_ato2 007-2010/2010/decreto/d7083.htm

Dourado, L. F. Oliveira, J. F., \& Santos, C. A. (2007). A qualidade da educação: conceitos e definições. Série Documental: Textos para Discussão, 24(22), 5-34.

Ferreira, G. V. (2016). Educação de Tempo Integral em Santarém: ações da Secretaria Municipal de Educação no período de 2008 a 2014 (Dissertação de Mestrado). Universidade Federal do Oeste Pará, Pará.

Frigotto, G. (2012). Educação Omnilateral. In Caldart, R. S. (Org.). Dicionário da Educação do Campo (pp. 267-274). São Paulo, SP: Expressão Popular. 
Lei n. 9.394, de 20 de dezembro de 1996. (1996, 23 de dezembro). Estabelece as Diretrizes e Bases da Educação Nacional. Recuperado

de: http://www.senado.gov.br/sf/legislacao

Lei ${ }^{\circ} 10.172$ de 9 de janeiro de 2001. Aprova o Plano Nacional de Educação. Recuperado de: http://www2.camara.leg.br/legin

Lei $\mathrm{n}^{\mathrm{o}}$ 7.441, de 2 de julho de 2010. (2010). Aprova o Plano Estadual de Educação e dá outras providências. Diário Oficial [República Federativa do Brasil Estado do Pará] 120(31), 707. Recuperado de: http://www.cee.pa.gov.br/sites/pdf

Lei $\mathrm{n}^{\circ}$ 13.005, de 25 de junho de 2014. (2017). Aprova o Plano Nacional de Educação (PNE). 2. Ed. Câmara dos Deputados, Brasília-DF.

Lei $\mathrm{n}^{\mathrm{o}}$ 8.186, de 23 de junho de 2015. (2015). Aprova o Plano Estadual de Educação - PEE e dá outras providências. Diário Oficial [República Federativa do Brasil - Estado do Pará], 125 (32). 913. Recuperado de: http://simec.mec.gov.br/sase/sasePA.

Libâneo, J. C. (2001). O sistema de organização e gestão da escola: teoria e prática. Goiânia, GO: Editora Alternativa.

Maurício, L. V. (2009). Escritos, representações e pressupostos da escola pública de horário integral. Em Aberto, 22(80), 15-31.

Oliveira. N. C. M., \& Cardoso, C. S. (2018). Educação Integral e(m) Tempo Integral no Município de Belém: momentos e movimentos. In Menezes, J. S. S. (Org.). Políticas e Gestão em educação em tempo integral: desafios contemporâneos (pp. 253-276). Curitiba, PR: Editora CRV.
Paro, V. H. (1988). Escola de tempo integral: desafio para o ensino público. São Paulo, SP: Cortez.

Pegorer, V. (2014). Educação Integral: um sonho possível e de realização necessária. São Paulo, SP: Textonovo.

Plano de Educação Integral para o Ensino Fundamental da Rede Estadual de Ensino do Pará. (2014). Centro de Estudos e Pesquisas em Educação, Cultura e Ação Comunitária - CENPEC. Pará.

Relatório do Núcleo de Estudos Tempos, Espaços e Educação Integral. NEEPHI. (2011). Universidade Federal do Estado do Rio de Janeiro. Recuperado de: http://www2.unirio.br/unirio/cchs/ppgedu/ neephi/historico.

Resolução no 002, de 24 de abril de 2012. (2012a). Dispõe sobre o projeto de escola de tempo integral. Secretaria de Estado de Educação. Pará.

Resolução n 003, de 24 de abril de 2012. (2012b). Dispõe sobre a organização e o funcionamento da escola de tempo integral. Secretaria de Estado de Educação. Pará.

Ribeiro, M. R. (2017). A relação entre currículo e educação integral em tempo integral: um estudo a partir da configuração curricular do Programa Mais Educação (Tese de Doutorado), Universidade Federal do Pará, Pará.

Santos, A. A. S. (2013). Gestão Pedagógica do programa Mais Educação: um olhar a partir da experiência da escola Teodora Bentes (Dissertação de Mestrado), Universidade Federal do Pará, Pará.

Sousa, L. E. S. (2016). Políticas de ampliação da jornada escolar: a implantação do Programa Mais Educação em Igarapé-Miri/PA (Dissertação de 
Oliveira, N. C. M., Souza, O. N. B., Correa, I. M., \& Cardoso, C. A. Q. (2020). Experimentações escolares da politica de educação integral e (m) Tempo Integral: uma análise das práticas efetivadas em escolas públicas de Belém - PA...

Mestrado). Universidade Federal do Pará, Pará.

Silva, S. L. C. (2017). O programa Mais Educação e sua Experiência numa Escola Pública de Belém (Trabalho de Conclusão de Curso). Universidade Federal do Pará, Pará.

Triviños, A. N. S. (1987). Introdução à pesquisa em ciências sociais: a pesquisa qualitativa em educação. São Paulo, SP: Atlas.

Vasconcelos, C. R. A. (2016). As experiências pedagógicas $d a$ implementação da política de educação em tempo integral nas escolas de campo na Amazônia paraense (Dissertação de Mestrado). Universidade Federal do Oeste Pará, Pará.

${ }^{\mathrm{i}}$ Resolução $\mathrm{n}^{\mathrm{o}}$ 002/2012 - dispõe sobre o Projeto Escola de Tempo Integral da SEDUC-PA. Publicação no 372265 (DOE-Pará - 25/04/2012).

ii Resolução n ${ }^{\circ}$ 003/2012 - dispõe sobre a organização e funcionamento da Escola de Tempo Integral da SEDUCPA. Publicação no 372269 (DOE-Pará - 25/04/2012).

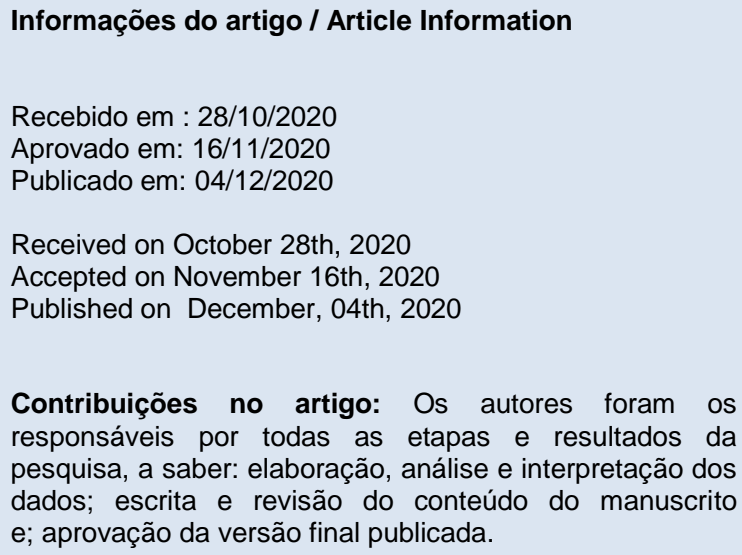

Contribuições no artigo: Os autores foram os responsáveis por todas as etapas e resultados da pesquisa, a saber: elaboração, análise e interpretação dos dados; escrita e revisão do conteúdo do manuscrito e; aprovação da versão final publicada.

Author Contributions: The author were responsible for the designing, delineating, analyzing and interpreting the data, production of the manuscript, critical revision of the content and approval of the final version published.

Conflitos de interesse: Os autores declararam não haver nenhum conflito de interesse referente a este artigo.

Conflict of Interest: None reported.

Orcid

Ney Cristina Monteiro de Oliveira

iD http://orcid.org/0000-0002-8091-5213

Orlando Nobre Bezerra de Souza

iD http://orcid.org/0000-0003-2606-0522

Izete Magno Correa

(iD)

http://orcid.org/0000-0003-0015-6868

Cintia Aurora Quaresma Cardoso

iD http://orcid.org/0000-0002-8929-1523

Como citar este artigo / How to cite this article

APA

Oliveira, N. C. M., Souza, O. N. B., Correa, I. M., \& Cardoso, C. A. Q. (2020). Experimentações escolares da política de educação integral e(m) Tempo Integral: uma análise das práticas efetivadas em escolas públicas de Belém - PA. Rev. Bras. Educ. Camp., 5, e10868. http://dx.doi.org/10.20873/uft.rbec.e10868

ABNT

OLIVEIRA, N. C. M.; SOUZA, O. N. B.; CORREA, I. M.; CARDOSO, C. A. Q. Experimentações escolares da política de educação integral e(m) Tempo Integral: uma análise das práticas efetivadas em escolas públicas de Belém - PA. Rev. Bras. Educ. Camp., Tocantinópolis, v. 5 ,

http://dx.doi.org/10.20873/uft.rbec.e10868 